\title{
Traumatic Pneumomediastinum: Case Report
} Travmatik Pnömomediastinum: Olgu Sunumu

\author{
Mustafa Uzkeser, Hüseyin Şahin, Sultan Tuna Akgöl Gür, Şahin Aslan \\ Department of Emergency Medicine, Faculty of Medicine, Atatürk University, Erzurum, Turkey
}

\begin{abstract}
Traumatic pneumomediastinum (TPM) is a rare entity. TPM may occur as a result of head, neck and thorax injury and rarely after oral injury. A 43-year-old man was brought to our ED approximately three hours after a motor vehicle accident (MVA) with complaints of angina pectoris and dyspnoea. His positive clinical findings were extensive bilateral subcutaneous emphysema and crepitation on his face, neck and trunk bilaterally. Electrocardiogram showed a first degree AV block. Supine chest x-ray, lateral neck x-ray and thorax CT showed subcutaneous and mediastinal air. After hospitalisation, bronchoscopy and endoscopy were performed with normal findings. On the second day, mediastinotomy was performed due to a pressure effect of the mediastinal emphysema. Complete resolution of the pneumothorax and mediastinal emphysema occurred gradually in the following days. He was discharged without any complication on the $6^{\text {th }}$ day. TPM is an important issue if pre-existing trachea or oesophagus injury is present.
\end{abstract}

Keywords: Trauma, mediastinum, mediastinal air, subcutaneous emphysema

Received: 28.02.2012 Accepted: 28.05.2012

\section{ÖZET}

Travmatik pnömomediastinum (TPM) nadir görülen bir tablodur. TPM baş, boyun, göğüs ve nadiren de ağız yaralanmaları sonucunda oluşabilir. Kırk üç yaşında erkek hasta motorlu taşıt kazasından yaklaşık 3 saat sonra göğüs ağrısı ve nefes darlığı ile Acil servise getirildi. Yapılan muayenede yüzde, boyunda ve göğüste yaygın bilateral cilt altı amfizemi ve krepitasyonu mevcuttu. Elektrokardiyografisinde birinci derece AV blok görüldü. Yatarak çekilen yatarak göğüs grafisi, yan boyun grafisi ve toraks tomografisinde ciltaltı ve mediastende hava görüldü. Hasta hospitalize edildikten sonra yapılan endoskopisi ve bronkoskopisi normal olarak değerlendirildi. Hospitalizasyonunun 2. gününde mediatinal amfizemin basınç etkisinde dolayı mediastinotomi yapıldı. Ilerleyen günlerde ortaya çıkan pnömothoraks ve mediastinal amfizem tamamen iyileşti. Hasta 6. gününde sekelsiz olarak taburcu edildi. Eğer trakea ve özefagus yaralanması önceden mevcut ise TPM önemli bir durumdur.

Anahtar Kelimeler: Travma, mediasten, mediastende hava, cilt altı amfizem

Geliş Tarihi: 28.02.2012 Kabul Tarihi: 28.05.2012

\section{Giriş}

Pnömomediastinum (PM) hastane kabulleri içinde \%0,13-\%1,4 oranında nadir görülen bir hastalıktır (1). PM genellikle primer (kendiliğinden) ve sekonder PM olmak üzere sınıflandırılır. Primer PM sebebi tam olarak açıklanamazken sekonder PM'a patolojik hastalıklar ve travma sebep olmaktadır (2). Travmatik pnömomediastinum (TPM) nadir görülen bir tablodur (3). TPM ciddi problemlere sebep olsa da radyolojik olarak teşhis edilebilir (2). Motorlu araç kazası sonucu acil servise getirilen cilt altı amfizem ve PM'si olan, zamanında ve yerinde yapılan müdahalelerle tam iyileşmenin sağlandığı bir vakayı sunmak istedik.

\section{Olgu Sunumu}

Üç saat önce motorlu araç kazası yapan 43 yaşında erkek hasta, 112 Acil Ambulansı tarafından Acil Servisimize getirildi. Hastanın getirildiğinde göğüs ağrııı ve nefes darlığı şikayetleri vardı. Hastanın şuuru açık, oryante ve koopere idi. Hastanın geliş anında ölçülen vital bulguları; tansiyon arteriyel: 148/86 mmHg, nabız: 112/dak, solunum sayısı: 20/dak, parmak ucu $\mathrm{O}_{2}$ saturasyonu: $\% 88$, ateş: $36,5^{\circ} \mathrm{C}$ idi. Hastaya maskeyle $\mathrm{O}_{2} 10 \mathrm{lt} / \mathrm{dk}$ solutulmaya başlandı. Hastanın özgeçmişinde bir hastalık öyküsü yoktu. Çekilen Elektrokardiyografisinde (EKG) birinci derece atriyoventriküler blok vardı (PR aralığı 0,25 saniye). Fizik muayenesinde yüzde boyunda ve bilateral göğüste yaygın cilt altı amfizemi ve krepitasyonu mevcuttu. Hastanın dinlemekle kalp atımılla uyumlu krepitasyon sesi duyulmaktaydı. Yatak başı Ekokardiyografisinde (EKO) kalp normal olarak değerlendirildi. Laboratuvar testle- 


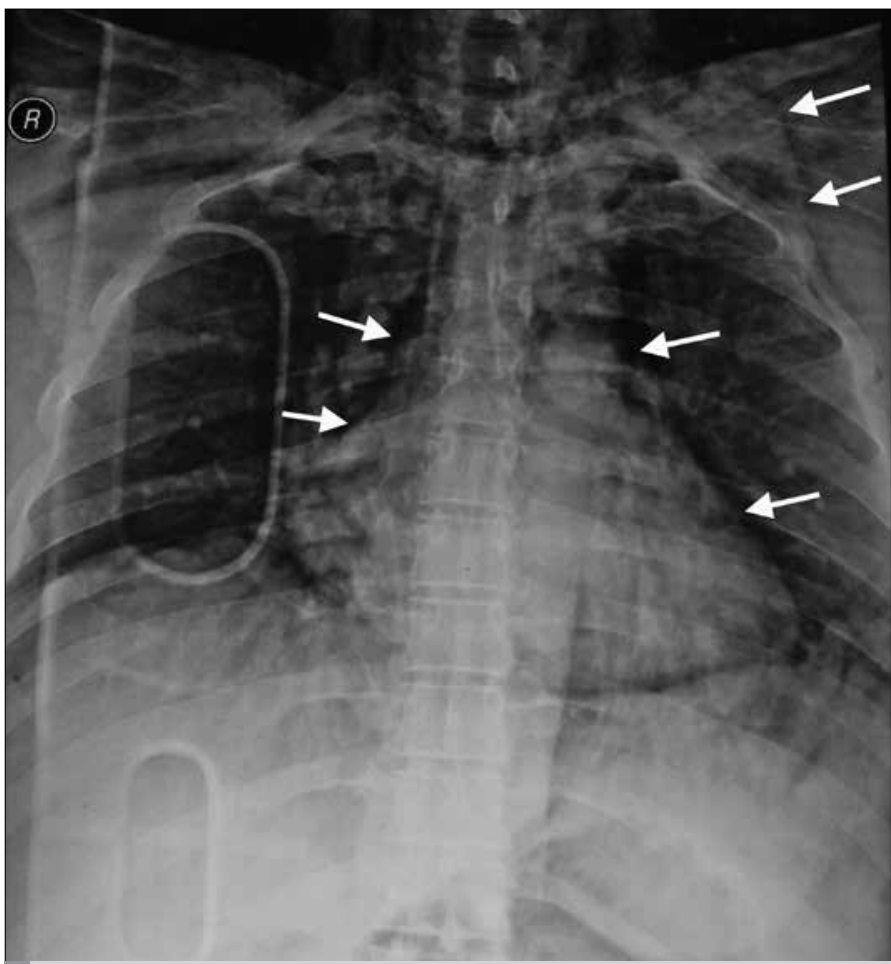

Resim 1. Toraks radyografisinde cilt altı (büyük ok) ve mediastende serbest hava (küçük ok) görünümleri

rinde sadece lökosit miktarı yüksekti (WBC: 20800/mm³). Radyolojik görüntülemelerinden toraks radyografisinde (Resim 1), yan boyun radyografisinde (Resim 2) ve toraks bilgisayarlı tomografisinde (BT) (Resim 3) cilt altı ve mediastende serbest hava vardı. Toraks BT'de ilave olarak her iki akciğerde kontüzyon alanları ve sternum kırığı mevcuttu. Hasta göğüs cerrahisi ile konsülte edilerek yatış planlandı. Hastaya acil olarak yapılan bronkoskopi ve endoskopisinde anormal bir bulguya rastlanılmadı. Hastaneye yatışının 2. gününde mediastinel amfizemin basınç etkisiyle nefes darlığının artması üzerine mediastinotomi yapıldı ve sağ akciğerde pnömotoraks geliştiği için tüp torakostomisi yapıldı. Hastanın takiplerinde mediastendeki amfizemde, pnömotoraksta ve EKG'sinde tam düzelme gözlendi. Hasta hastaneye yatışının 6. gününde sekelsiz olarak taburcu edildi.

\section{Tartışma}

Ateroskleroz ve kanser ölümlerinden sonra en sık ölüm nedeni toraks travmalarıdır. Tüm vücut travmalarından ölümlerin de dörtte biri toraks travmalarından olmaktadır (4). Toraks travmalarının 2/3'ü motorlu araç kazalarına bağlı oluşmaktadır. Toraks travmalarına bağlı izole PM gelişimi nadir bir durumdur.

Mediastende serbest halde hava bulunmasına PM denmektedir (5). TPM toraks travmalarına bağlı görülmekle birlikte; baş, boyun, ve nadiren ağız yaralanmalarına bağlı da görülebilir (6). TPM'li hastalar genellikle göğüs ağrısı, nefes darlığı ve siyanoz ile acil servislere baş vururabilirler (7). Bizim vakamızda motorlu araç kazasına bağlı künt toraks yaralanmasına maruz kalmıştır. Bunun sonucunda da sternal kırık olmasına rağmen açık yaralanması olmayan hastamızda siyanoz gözlenmezken göğüs ağrısı ve nefes darlığı bulunmaktaydı.

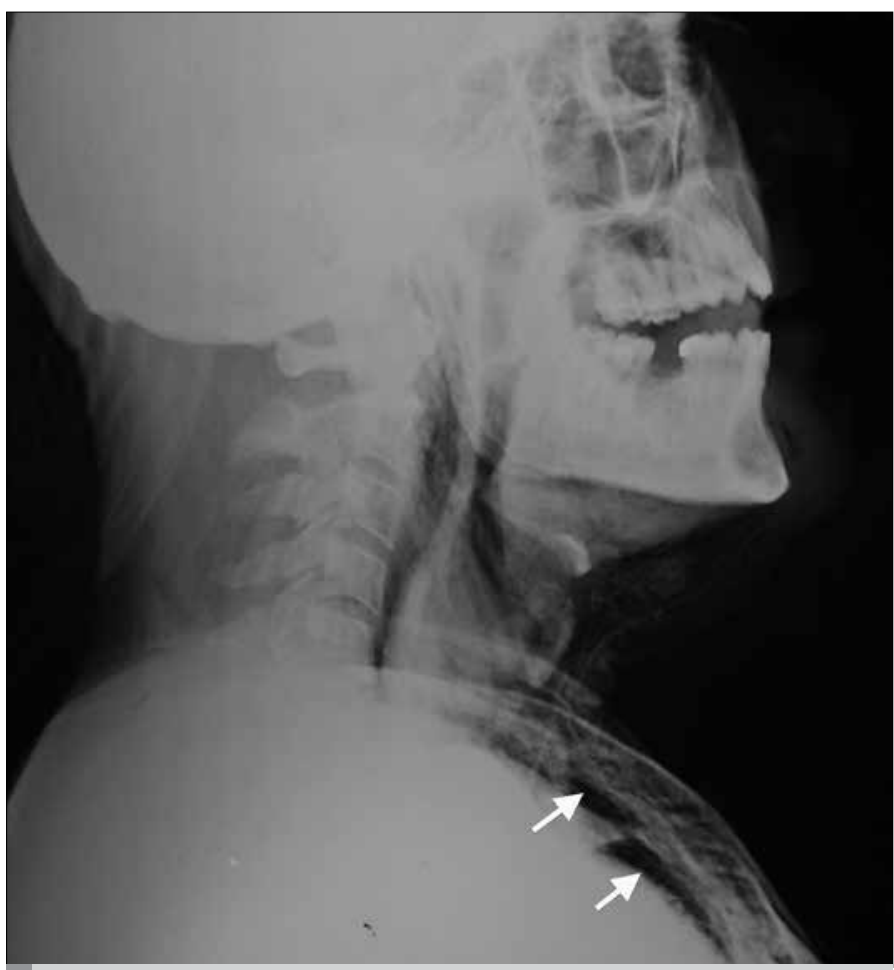

Resim 2. Yan boyun radyografisinde cilt altı serbest hava görünümü

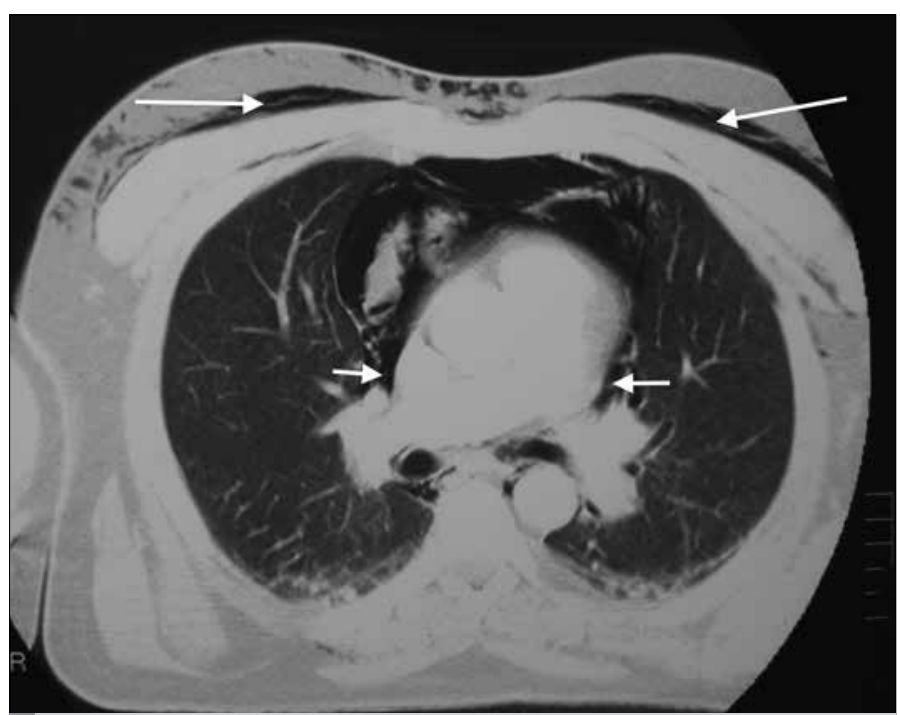

Resim 3. Toraks bilgisayarlı tomografisinde cilt altı (büyük ok) ve mediastende serbest hava (küçük ok) görünümü

Travma sonrası gelişen PM vakalarında EKG'de T dalga inversiyonu, R dalga progresyon kaybı ve düşük voltajlı QRS gibi değişiklikleri görülebilir. Fakat kendiliğinden PM ve TPM hastalarının çoğunda kalpte kalıcı bir hasar gösterilememiştir $(4,8)$. EKG'de görülen değişikliklerin sebebi olarak pnömomediastinuma bağlı kalbin bulunduğu yerde dönme ve yer değiştirmesi, sağ ventrikülün genişlemesi ve mediastendeki hava tarafından kalbin izole edilmesi gösterilmektedir (8). 
Bizim hastamızda travmaya bağlı olarak kalpte herhangi bir yaralanma durumu tespit edilemedi. Ancak travma sonrası hastanın EKG'sinde yeni başlayan değişiklikler tespit edilmiştir. Kaldı ki EKG'deki bu değişiklikler takip ve tedavi esnasında tamamen düzelmiş olması, bu patolojinin hastanın yüksek enerjili künt toraks travmasına maruz kalmasına bağlı geliştiğini düşündürmektedir. Ancak EKG'deki bu değişiklik travmatik pnömomediastinuma bağlı olabileceği gibi künt toraks travmasının direkt etkisinden de kaynaklanabilir.

Pnömomediastinumlu hastaların toraks muayenelerinde kalbin etrafındaki havayla dokulara sürtünmesiyle açığa çıkan "krepitasyon" sesine ilk defa 1937 yılında Louis Hamman tarafından tanımlandığı için "Hamman bulgusu" denmiştir (9). Hastamızın muayenesinde dinlemekle kalp atımıyla uyumlu olarak duyduğumuz krepitasyon sesi de literatürde tanımlanan Hamman bulgusuna işaret etmektedir.

Primer PM'lu hastaların cilt altı amfizemi ve PM'u genellikle müdahalesiz 3-6 gün içinde gerilemekte iken, travmatik PM'li hastalarda oluşan ek patolojiler bu sürenin belirlenmesinde etkin rol oynamaktadırlar (10). Bizim vakamızda da hastanın mediastenindeki havanın artması ve basınç etkisiyle semptomlarındaki kötüleşme sonucu mediastinotomi yapılmış ve arkasından da sağ pnömotoraks tanısıyla tüp torakostomisi uygulanmıştır. Hastamızda gelişen komplikasyona erkenden ve yerinde müdahale edilmesiyle gelişebilecek ciddi problemler önlenmiş ve hastanın sekelsiz olarak taburcu edilmesi sağlanmıştır.

\section{Sonuç}

Travmatik pnömomediastinum nadir olarak görülmektedir. Kendiliğinden PM'li hastaların genellikle kısa sürede komplikasyonsuz iyileşmeleri TPM'li hastalarda ek problemlerin olması komplikasyonların görülmesine ve iyileşme sürecinde uzamalara sebep olmaktadır. Künt toraks travmasının varlığında kalpte etkilenmenin olup olmadığı araştııılmalı ve takiplerinde yakın gözlem altında tutulması gerekmektedir.

\section{Conflict of Interest}

No conflict of interest was declared by the authors.

Peer-review: Externally peer-reviewed.

\section{Author Contributions}

Concept - Ş.A.; Design - M.U.; Supervision - Ş.A.; Funding - M.U.; Materials
- M.U., H.Ş., S.T.A.G.; Data Collection and/or Processing - M.U., H.Ş., S.T.A.G.; Analysis and/or Interpretation - M.U.; Literature Review - M.U.; Writer M.U.; Critical Review - Ş.A.

\section{Çıkar Çatışması}

Yazarlar herhangi bir çıkar çatışması bildirmemişlerdir.

Hakem değerlendirmesi: Dış bağımsız.

\section{Yazar Katkıları}

Fikir - Ş.A.; Tasarım - M.U.; Denetleme - Ş.A.; Kaynaklar - M.U.; Malzemeler - M.U., H.Ş., S.T.A.G.; Veri toplanması ve/veya işlemesi - M.U., H.S., S.T.A.G.; Analiz ve/veya yorum - M.U.; Literatür taraması - M.U.; Yazıyı yazan - M.U.; Eleştirel İnceleme - Ş.A.

\section{Kaynaklar}

1. Maravelli AJ, Skiendzielewski JJ, Snover W. Pneumomediastinum acquired by glass blowing. J Emerg Med 2000; 19: 145-7. [CrossRef]

2. Caceres M, Braud RL, Maekawa R, Weiman DS, Garrett HE, Jr. Secondary pneumomediastinum: a retrospective comparative analysis. Lung 2009; 187: 341-6. [CrossRef]

3. Lopez-Pelaez MF, Roldan J, Mateo S. Cervical emphysema, pneumomediastinum, and pneumothorax following self-induced oral injury: report of four cases and review of the literature. Chest 2001; 120: 306-9. [CrossRef]

4. Emet M, Akoz A, Aslan S, Saritas A, Cakir Z, Acemoglu H. Assessment of cardiac injury in patients with blunt chest trauma. Eur J Trauma Emerg S 2010; 36: 441-7. [CrossRef]

5. Chu CM, Leung YY, Hui JY, Hung IF, Chan VL, Leung WS, et al. Spontaneous pneumomediastinum in patients with severe acute respiratory syndrome. The European respiratory journal: official journal of the European Society for Clinical Respiratory Physiology 2004; 23: 802-4.

6. Demers G, Camp JL, Bennett D. Pneumomediastinum caused by isolated oral-facial trauma. Am J Emerg Med 2011; 29: 841.e3-8.

7. Uscategui-Florez T, Martinez-Devesa P, Gupta D. Mucosal tear in the oropharynx leading to pneumopericardium and pneumomediastinum: an unusual complication of blunt trauma to the face and neck. The surgeon: journal of the Royal Colleges of Surgeons of Edinburgh and Ireland 2006; 4: 179-82.

8. BrearleyWD, Jr., Taylor L, 3rd, Haley MW, Littmann L. Pneumomediastinum mimicking acute ST-segment elevation myocardial infarction International Journal of Cardiology 2007; 117: e73-5. [CrossRef]

9. Hamman L. Spontaneous interstitial emphysema of the lungs. Tr Assos Am Physicians 1937; 52: 311-9.

10. Ralph-Edwards AC, Pearson FG. Atypical presentation of spontaneous pneumomediastinum. Ann Thorac Surg 1994; 58: 1758-60. [CrossRef] 